\title{
THE USE OF ARTIFICIAL NEURAL NETWORKS IN THE THEORETICAL INVESTIGATION OF FAULTS IN TRANSMISSION LINES
}

\author{
T. C. Madueme ${ }^{1}$ and P. G. Wokoro ${ }^{2, *}$ \\ 1, 2 Department Of Electrical EngineERING, University OF Nigeria, NSUKKa, ENUGU STATE. NigERIA \\ Email addresses:1 theophilus.madueme@unn.edu.ng, ${ }^{2}$ preyewokoro@gmail.com
}

\begin{abstract}
This paper describes the development of a fast, efficient, artificial neural network (ANN) based fault diagnostic system (FDS) for the location of fault on transmission lines. The principal functions of this diagnostic system are: detection of fault occurrence, identification of faulted sections and classification of faults into types. This has been achieved through a cascaded, multilayer ANN structure using the back-propagation (BP) learning algorithm. This paper shows that the FDS accurately identifies High Impedance Faults, which are relatively difficult to identify with other methods. Test results are simulated and generated in MATLAB using Apo 132KV transmission line in Apo transmission substation, Abuja. These results amply demonstrate the capability of the FDS in terms of accuracy and speed with respect to detection, localization, and classification of faults in transmission lines.
\end{abstract}

Keywords: Transmission lines, Fault classifier, Fault locator, artificial neural networks.

\section{INTRODUCTION}

Restoration of power supply following faults is an important responsibility of power system operators. Rapid and accurate fault diagnosis (detection, fault section identification, and type classification) plays a central role in the fulfillment of this responsibility for maintaining continuous and reliable power supply. At the same time, power systems have increased in size and complexity. Both factors increase the risk of major power outages. After a blackout, power needs to be restored as quickly and reliably as possible and, consequently, detailed restoration plans are necessary [1-5].

Previous research for detecting faults on transmission lines includes methods based on monitoring power frequency quantities such as load and ground current levels and sequence voltages and currents on the source side of the fault location. Some researchers used the noise and harmonics produced by arcing as a fault signature [2, 4-10].

A transmission line is one of the most important components of power system which connects the generating station with distribution system. The probability of fault occurring on a transmission line is quite large as it is exposed to open environmental conditions. The various types of faults occurring on a transmission line are: single line to ground fault (L-G), double line to ground faults (LL-G), line to line faults (L-L) and triple line to ground faults (3phase). So it becomes a prerequisite for faster detection and clearance of faults and henceforth ensuring security and stability of the system as a whole. The purpose of a protective relays is to clear the fault as quickly as possible, minimize the damage caused due to fault and restore the line quickly. As a result of this it is important to know about the nature of the fault that occurred in the line and its exact location [11-19].

The purpose of this paper is to remedy this situation by developing an FDS for transmission networks based on ANN methodology. The multilayer feedforward network with the back- propagation (BP) learning algorithm is employed in this work. The proposed FDS is characterized by the following features: (1) high computational efficiency resulting in fast response; (2) use of only local substation measurements without need for additional telemetering; (3) High Impedance faults (HIFs) and Low Impedance faults (LIFs) are identified in a reliable fashion; (4) adaptable for use with a wide range of network topologies; (5) uncomplicated structure for easy implementation; (6) efficient overall performance. 


\section{ANN STURUCTURES}

Artificial Neural networks (ANN) are simplified models of biological neuron systems. An ANN consists of a massively parallel distributed processing system made of highly interconnected neural computing elements called as "Neurons", which has the ability to learn and thereby acquire knowledge. ANN comprises of a number of neurons which forms the basic processing unit. Each neuron is further connected to other neurons by links. Every neuron receives a number of inputs which are modified by 'weights'. The synaptic weights would either strengthen or weaken the signal which is processed further. To generate the final output the sum of the weighted output is passed on to a non-linear filter called as 'activation function' or 'Transfer function' or 'Squash function', plus a threshold value called 'bias' which releases the output. Figure 1 shows the model of ANN [17]. Although the basic concept behind relays remains the same, the digital technology has had a significant influence on the way relays operate and have offered several improvements over traditional electromechanical relays.
The main goal of this paper is to design, develop, test and implement a complete strategy for the fault diagnosis as shown in Figure 2. Initially, the entire data that is collected is subdivided into two sets namely the training and the testing data sets

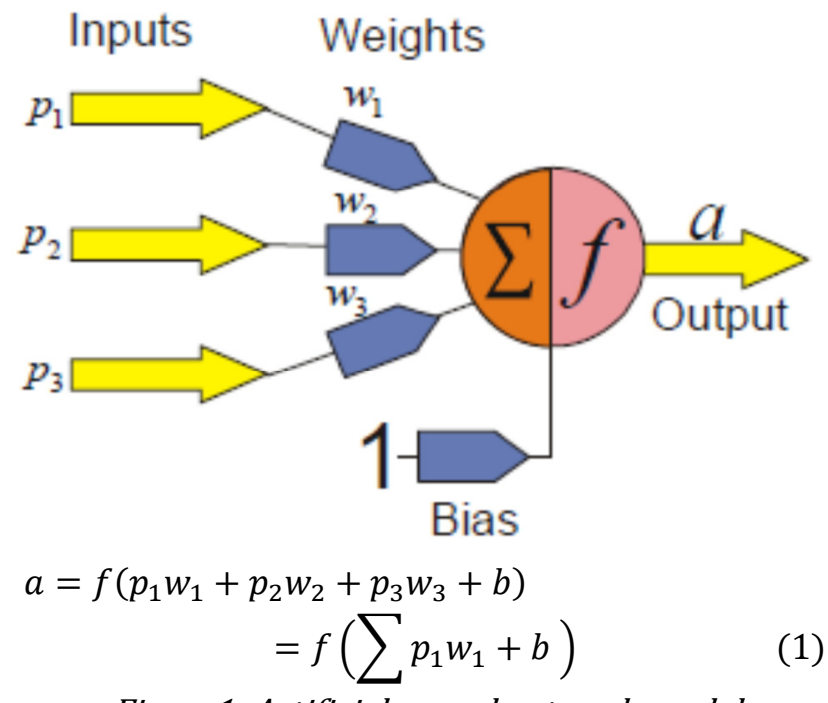

Figure1: Artificial neural network model

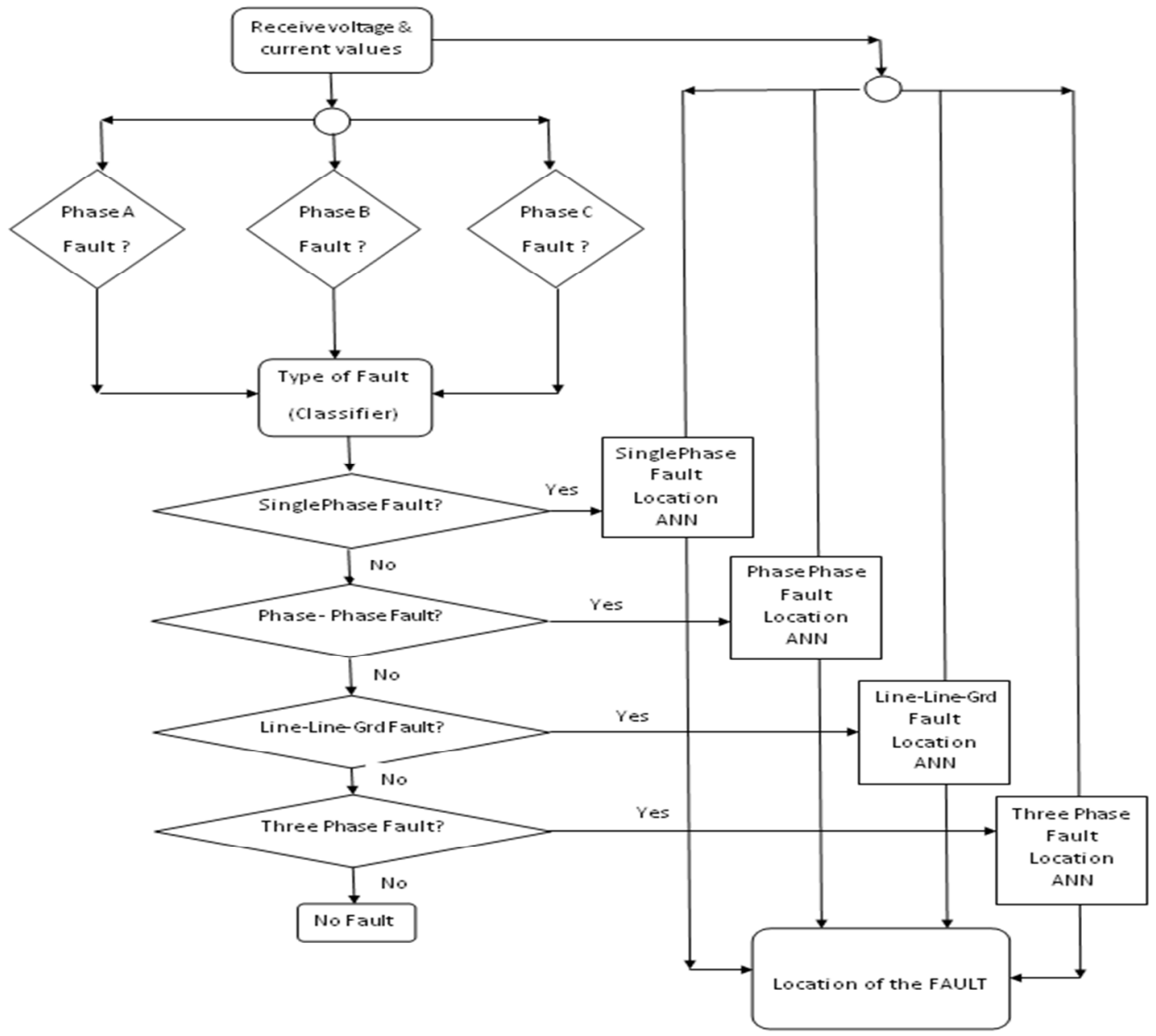

Figure 2: A flow chart showing the outline of the ANN 


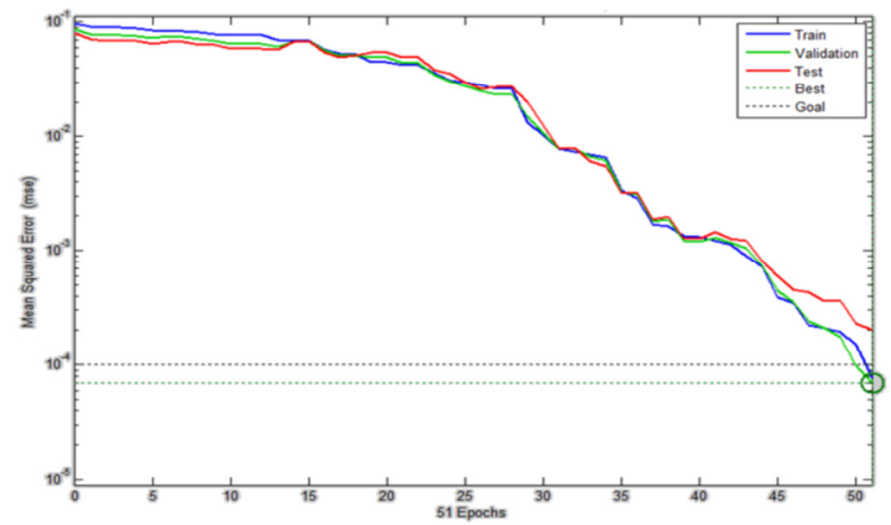

Figure 3: Mean-square error performance of the network (6-10-5-3-1)

The first step in the process is fault detection. Once we know that a fault has occurred on the transmission line, the next step is to classify the fault into the different categories based on the phases that are faulted.

Then, the third step is to pin-point the position of the fault on the transmission line. This paper sets out to propose an integrated method to perform each of these tasks using artificial neural networks. A backpropagation based neural network has been used for the purpose of fault detection and another similar one for the purpose of fault classification. For each of the different kinds of faults, separate neural networks have been employed for the purpose of fault location. Each of these steps has been depicted in the flowchart shown in Figure 2.

\section{TRAINING METHOD}

Several different training algorithms for ANN are available [18]. All these algorithms use the gradient of the performance function to determine how to adjust the weights to minimize performance. The gradient is determined using a technique called back propagation, which involves performing computations backward through the network. Taking speed and memory allocation into account many algorithms are available for implementing the back propagation method. Levenberg-Marquardt optimization technique is used in the implemented ANN structure [19-20].

Simulations were carried out for different fault scenarios in order to get various fault patterns. The system model as well as ANN training was performed using MATLAB 7.0. The simulations were carried out for different fault types such as LG, LL, LLG and Three Phase faults.

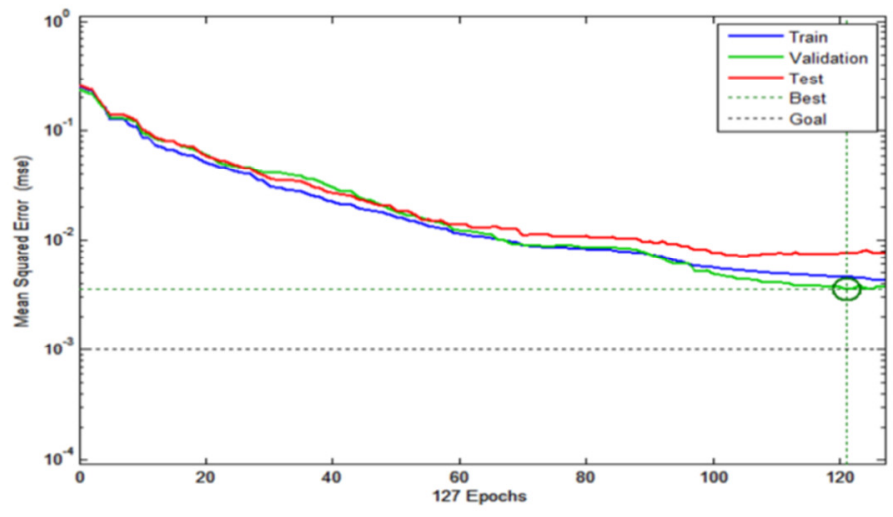

Figure 4: Mean-square error performance of the network with configuration (6-35-4).

\section{RESULTS AND DISCUSSIONS}

\subsection{Fault Detection:}

In this first stage which is the fault detection phase, the network takes in six inputs at a time, which are the voltages and currents for all the three phases (scaled with respect to the pre-fault values) for ten different faults and also for no-fault case. The output of the neural network is just a yes or a no ( 1 or 0 ) depending on whether or not a fault has been detected.

After extensive simulations it was seen that the neural network configuration of 6-10-5-3-1 with mean square error value below 0.0001 which is $6.9776 \mathrm{e}^{-5}$ has been chosen as the ideal ANN for the purpose of fault detection. The mean square error performance of the network with configuration (6-10-5-3-1) is shown in Figure 3.

\subsection{Fault Classification}

Once a fault has been detected on the power line, the next step is to identify the type of fault. Fault classifiers based on neural networks have been extensively proposed and used in the past and almost all of these classifiers made use of multilayer perception neural network and employed the backpropagation learning strategy. After all simulations it was seen that the neural network configuration of (635-4), with an overall mean square error of 0.0035986 has been chosen as the ideal ANN for the purpose of fault classification. The mean square error (MSE) performance of the network with configuration (6-35-4) is shown in Figure 4.

\subsection{Fault Location}

This is all about the design, development and the implementation of the neural network based fault locators for each of the various types of faults. This also forms the third step in the entire process of fault location after the inception of the fault. 


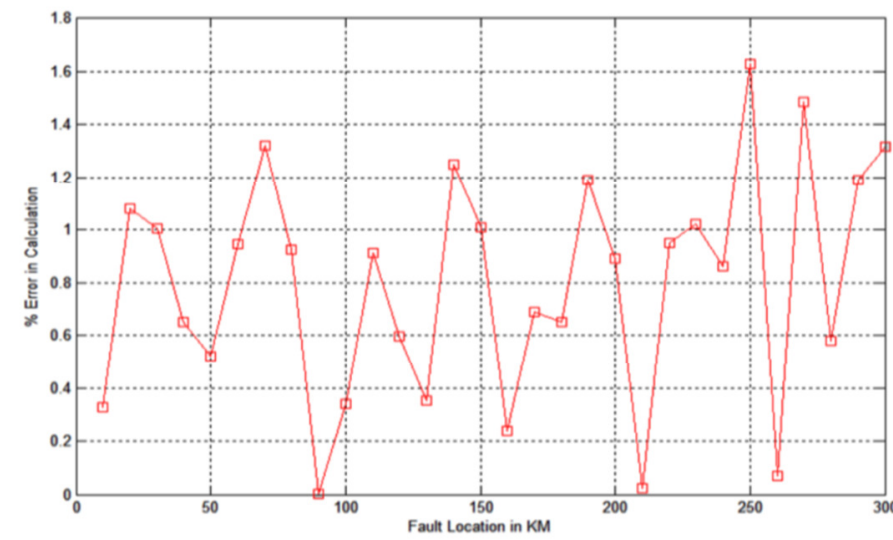

Figure 5: Test phase performance of the ANN with configuration (6-7-1).

\subsubsection{Single Line to Ground Fault}

Since we can detect the occurrence of a fault on a transmission line and also classify the fault into the various fault categories, the next step is to pin-point the location of the fault from either ends of the transmission line. In order to train the neural network, several single phase faults have been simulated on the transmission line model. For each of the three phases, faults have been simulated at every $3 \mathrm{~km}$ on the $300 \mathrm{~km}$ long transmission line. This marks the end of the training of the neural network for single line to ground faults.

In order to test the performance of this network, 100 different single phase faults have been simulated on different phases with the fault distance being increased by $10 \mathrm{~km}$ in each case and the percentage error in calculated output has been determined. It is seen that the maximum error is around 1.65 percent which is very satisfactory. It is to be noted that the average error in fault location is just $0.89 \%$. The test phase performance and the mean square error performance of the ANN with configuration (6-7-1) are shown in Figure 5 and Figure 6 respectively.

Table 1 shows the percentage errors in Fault location as a function of Fault Distance and Fault Resistance.

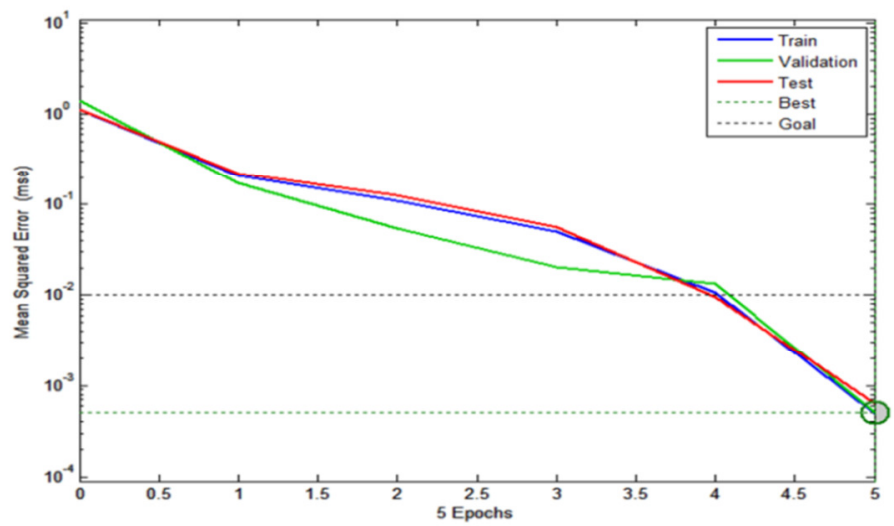

Figure 6: Mean-square error performance of the network with configuration (6-7-1).

Two different cases have been considered (shown in adjacent columns), one with a fault resistance of $20 \mathrm{ohms}$ and another with a fault resistance of $60 \mathrm{ohms}$. It is to be noted that the resistance of $20 \mathrm{ohms}$ was used as a part of training data set and hence the average percentage different fault resistance of $60 \mathrm{ohms}$ which is relatively very high and is not a part of the training set. Hence, the performance of the neural network in this case illustrates its ability to generalize and react upon new data. It is to be noted that the average error in this case is just $0.878 \%$ which is very satisfactory. Thus the neural networks performance is considered satisfactory and can be used for the purpose of single line - ground fault location.

\subsubsection{Line to Line Fault}

Now that we can detect the occurrence of a fault on a transmission line and also classify the fault into the various fault categories, the next step is to pin-point the location of the fault from either ends of the transmission line. Three possible line - line faults exist (A-B, B-C, C-A), corresponding to each of the three phases $(A, B$ or $C)$ being faulted.

Table 1: Percentage errors as a function of fault distance and fault resistance for the ANN chosen for single line - ground fault location.

\begin{tabular}{|c|c|c|c|c|c|c|}
\hline \multirow[t]{2}{*}{$\begin{array}{l}\text { Serial } \\
\text { No. }\end{array}$} & \multicolumn{3}{|c|}{$\%$ Error vs. fault distance (Fault Resistance=20 2 ) } & \multicolumn{3}{|c|}{$\begin{array}{l}\text { \% Error vs. fault distance (Fault Resistance }= \\
60 \Omega \text { ) }\end{array}$} \\
\hline & $\begin{array}{l}\text { Fault Distance } \\
(\mathrm{Km})\end{array}$ & $\begin{array}{l}\text { Measured Fault } \\
\text { Location }\end{array}$ & $\begin{array}{l}\text { Percentage } \\
\text { Error }\end{array}$ & $\begin{array}{l}\text { Fault Distance } \\
(\mathrm{Km})\end{array}$ & $\begin{array}{l}\text { Measured Fault } \\
\text { Location }\end{array}$ & $\begin{array}{l}\text { Percentage } \\
\text { Error }\end{array}$ \\
\hline 1 & 25 & 25.49 & 0.163 & 50 & 51.56 & 0.52 \\
\hline 2 & 75 & 75.58 & 0.287 & 100 & 101.02 & 0.34 \\
\hline 3 & 125 & 125.12 & 0.04 & 150 & 153.03 & 1.01 \\
\hline 4 & 175 & 175.09 & 0.03 & 200 & 202.67 & 0.89 \\
\hline 5 & 225 & 225.91 & 0.303 & 250 & 254.89 & 1.63 \\
\hline
\end{tabular}


In order to test the performance of this network, 100 different phase to phase faults have been simulated on different phases with the fault distance being increased by $10 \mathrm{Km}$ in each case and the percentage error in calculated output has been determined. It can be seen that the best MSE performance of this neural network is 0.002089 which is below the MSE goal of 0.01 . It was found that the correlation coefficient between the outputs and the targets was 0.98648 which is a decently good regression fit for this neural network. It also can be seen that the maximum error is around 1.7 percent which is very satisfactory. It is to be noted that the average error in fault location is just 0.97 percent. Hence, this neural network has been chosen as the ideal network for the purpose of line line fault location on transmission lines. The test phase performance and the mean square error performance of the network with configuration (6-105-1) are shown in Figure 7 and Figure 8 respectively. Table 2 shows the percentage errors in Fault location as a function of Fault Distance and Fault Resistance. Two different cases have been considered (shown in adjacent columns), one with a fault resistance of 20 ohms and another with a fault resistance of 60 ohms. It is to be noted that the resistance of $20 \mathrm{ohms}$ was used as a part of training data set and hence the average percentage error in fault location in this case is just $0.1386 \%$. The second case illustrates the same with a different fault resistance of $60 \mathrm{ohms}$ which is relatively very high and is not a part of the training set.

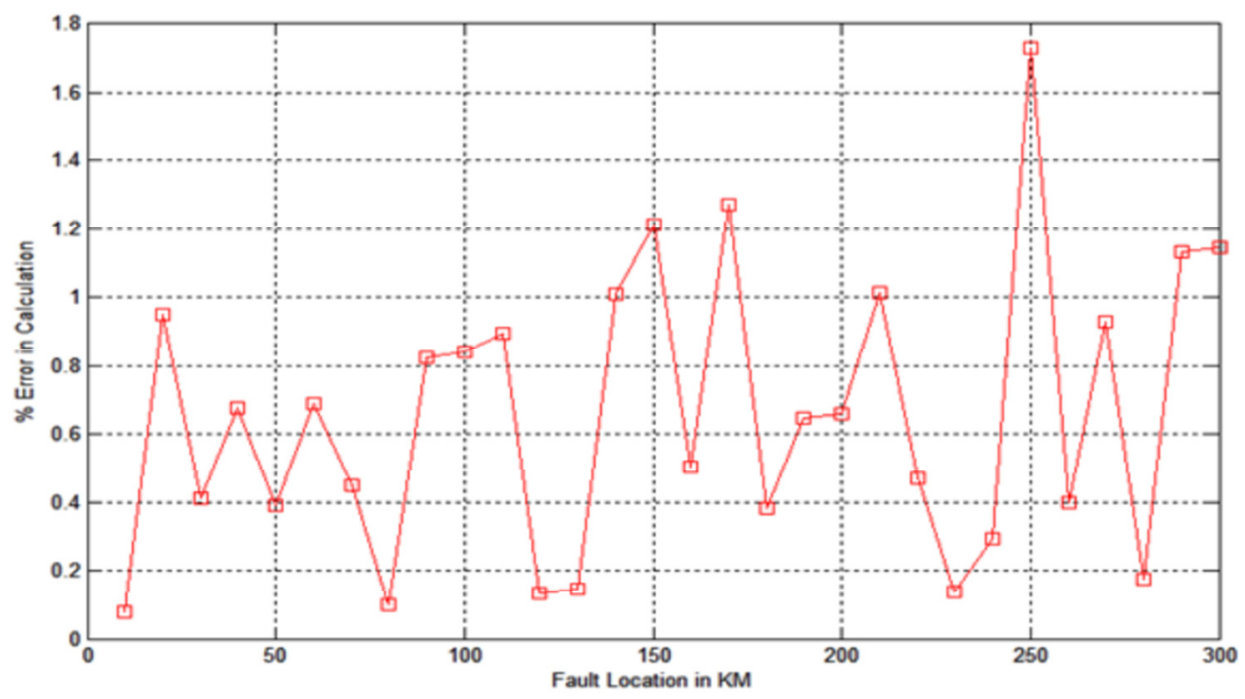

Figure 7: Test phase performance of the neural network with configuration (6-10-5-1).

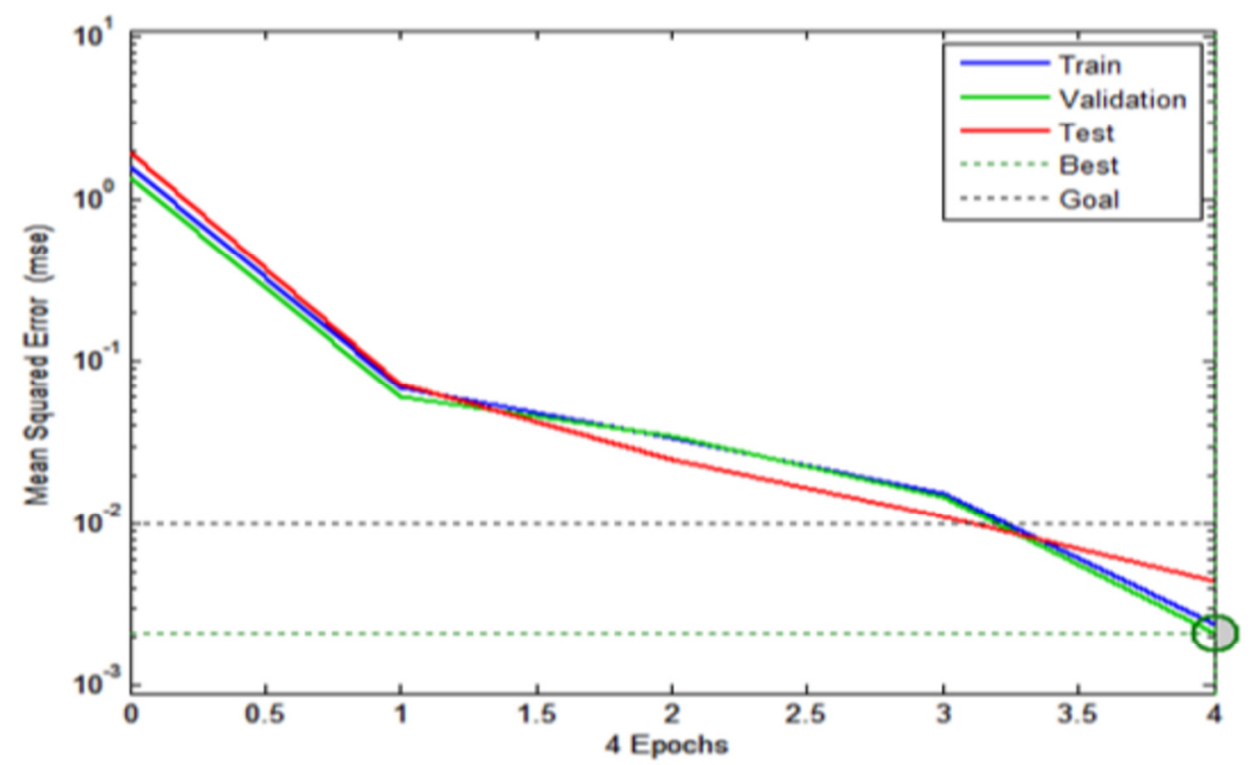

Figure 8: Mean Square Error performance of the ANN with configuration (6-10-5-1). 
Use of Artificial Neural Networks In Theoretical Investigation of Faults in Transmission Lines. T. C. Madueme \& P. G. Wokoro

Table 2: Percentage errors as a function of fault distance and fault resistance for the ANN chosen for line - line fault location.

\begin{tabular}{|c|c|c|c|c|c|c|}
\hline \multirow[t]{2}{*}{ Serial No. } & \multicolumn{3}{|c|}{$\begin{array}{l}\text { \% Error vs. fault distance } \\
(\text { Fault Resistance }=20 \Omega)\end{array}$} & \multicolumn{3}{|c|}{$\begin{array}{l}\% \text { Error vs. fault distance } \\
\text { (Fault Resistance }=60 \Omega \text { ) }\end{array}$} \\
\hline & $\begin{array}{l}\text { Fault Distance } \\
(\mathrm{Km})\end{array}$ & $\begin{array}{l}\text { Measured Fault } \\
\text { Location }\end{array}$ & $\begin{array}{l}\text { Percentage } \\
\text { Error }\end{array}$ & $\begin{array}{l}\text { Fault Distance } \\
(\mathrm{Km})\end{array}$ & $\begin{array}{l}\text { Measured } \\
\text { Fault } \\
\text { Location }\end{array}$ & $\begin{array}{l}\text { Percentage } \\
\text { Error }\end{array}$ \\
\hline 1 & 25 & 25.03 & 0.01 & 50 & 51.17 & 0.39 \\
\hline 2 & 75 & 75.39 & 0.13 & 100 & 102.52 & 0.84 \\
\hline 3 & 125 & 125.67 & 0.223 & 150 & 153.63 & 1.21 \\
\hline 4 & 175 & 175.14 & 0.047 & 200 & 201.98 & 0.66 \\
\hline 5 & 225 & 225.85 & 0.283 & 250 & 255.19 & 1.73 \\
\hline
\end{tabular}

Hence, the performance of the neural network in this case illustrates its ability to generalize and react upon new data. It is to be noted that the average error in this case is just $0.966 \%$ which is still very satisfactory. Thus the neural networks performance is considered satisfactory and can be used for the purpose of line line fault location.

\subsubsection{Double Line to Ground Fault}

The third category of faults is the double line -ground faults. Three possible double line - ground faults exist which are denoted as ABG, BCG and ACG (based on which two of the three phases $A, B$ and $C$ are faulted). In order to test the performance of this network, 100 different double line - ground faults have been simulated on different phases with the fault distance being increased by $10 \mathrm{Km}$ in each case and the percentage error in calculated output has been determined. It can be seen that the maximum error is around 1.71 percent which is very satisfactory. It is to be noted that the average error in fault location is just 0.863 percent. At the end this neural network has been chosen as the ideal network for the purpose of double line - ground fault location on transmission lines. And the best linear regression fit between the outputs and the targets is seen in the last graph. The correlation coefficient in this case is found to be 0.99329 which is very good regression fit. It can be seen that the best MSE performance of this neural network is 0.00159395 which is below the MSE goal of 0.01 (denoted by the black dotted line in the MSE). The test phase performance and the mean square error performance of the network with configuration (6-21-11-1) are shown in Figure 9 and Figure 10 respectively.

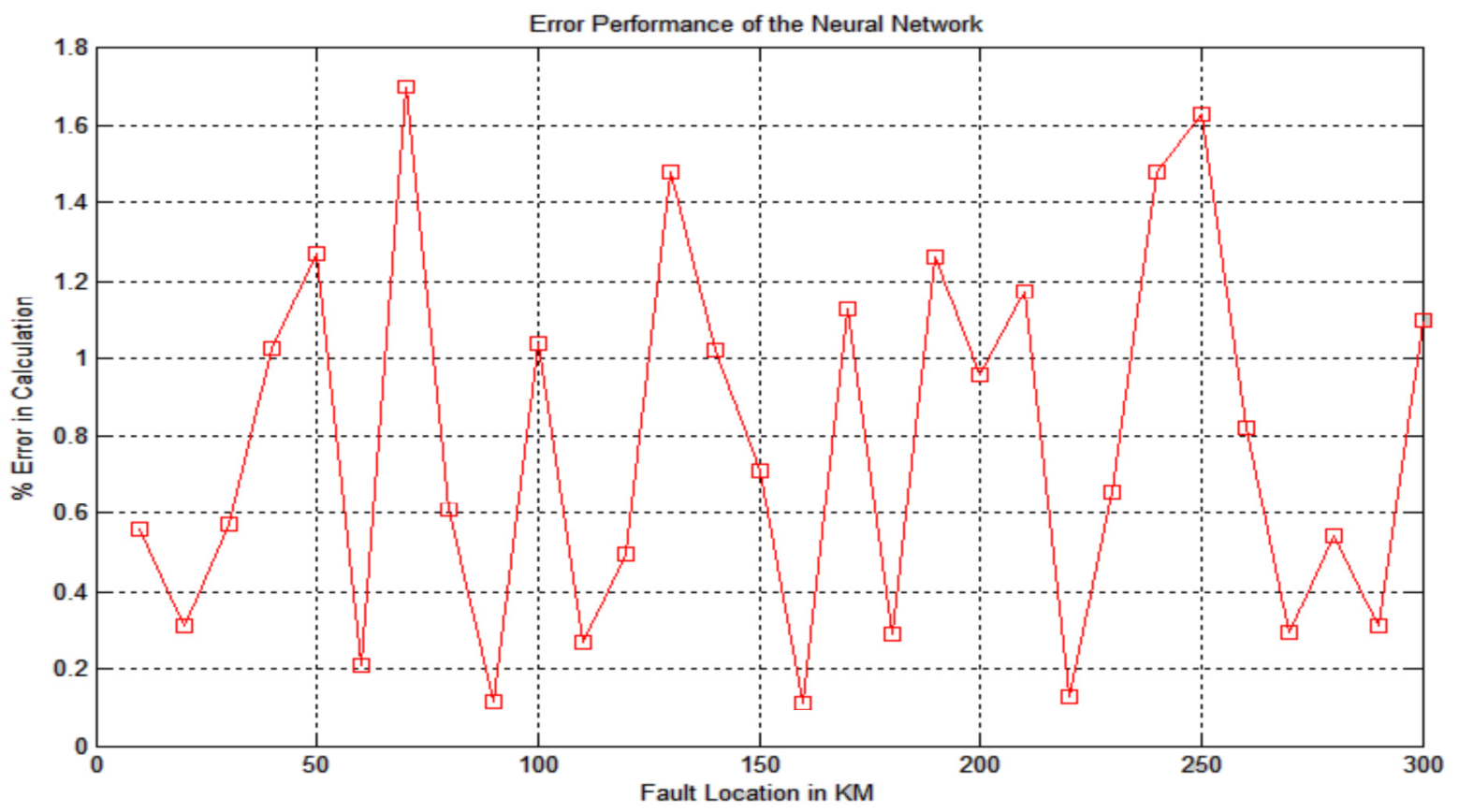

Figure 9: Test phase performance of the ANN (6-21-11-1). 


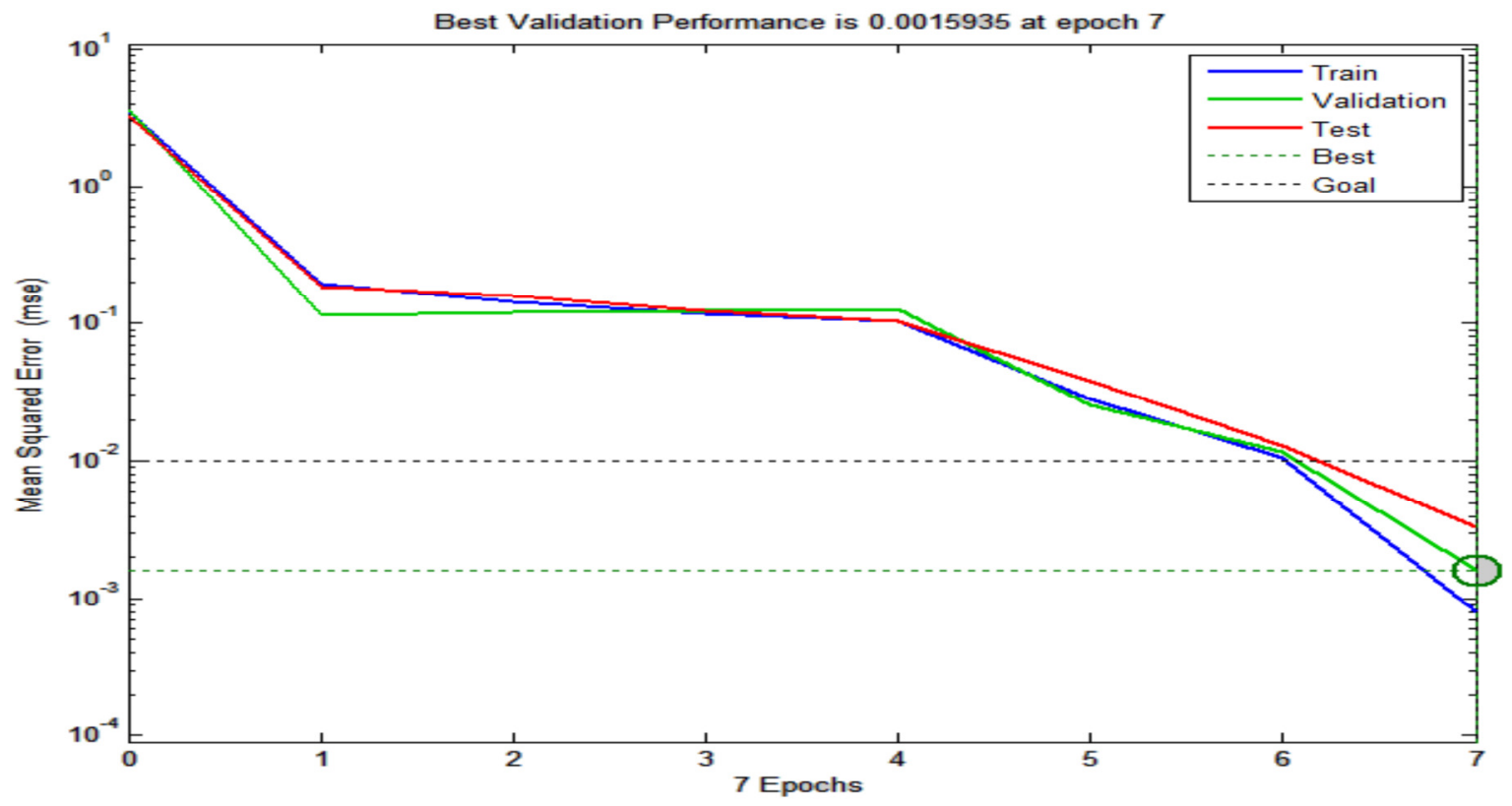

Figure 10: Mean Square Error performance of the ANN with configuration (6-21-11-1).

Table 3 shows the percentage error in Fault location as a function of Fault Distance and Fault Resistance. Two different cases have been considered (shown in adjacent columns), one with a fault resistance of 20 ohms and another with a fault resistance of $60 \mathrm{ohms}$. It is to be noted that the resistance of $20 \mathrm{ohms}$ was used as a part of training data set and hence the average percentage error in fault location in this case is just $0.091 \%$. The second case illustrates the same with a different fault resistance of $60 \mathrm{ohms}$ which is relatively very high and is not a part of the training set. Hence, the performance of the neural network in this case illustrates its ability to generalize and react upon new data. It is to be noted that the average error in this case is just $1.122 \%$ which is still acceptable. Thus the neural networks performance is considered satisfactory and can be used for the purpose of double line - ground fault location.

\subsubsection{Three Phase Fault}

The fourth and the final category of faults are the three phase faults. There exists only one kind of three phase faults which is denoted as $A B C$ fault where in all the three phases A, B and C are faulted.

In order to test the performance of this network, 100 different three phase faults have been simulated on the transmission line with the fault distance being incremented by $10 \mathrm{Km}$ in each case and the percentage error in ANN's output has been calculated. It can be seen that the maximum error is around 1.62 percent which is very satisfactory. It is to be noted that the average error in fault location is just 0.677 percent. Hence, this neural network has been chosen as the ideal network for the purpose of three phase fault location on transmission lines. The correlation coefficient ( $r$ ) as mentioned earlier is a measure of how well the neural network relates the outputs and the targets. The closer the value of $r$ is, to 1 , the better the performance of the neural network.

Table 3: Percentage errors as a function of fault distance and fault resistance for the ANN chosen for double line ground fault location.

\begin{tabular}{|c|c|c|c|c|c|c|}
\hline \multirow[t]{2}{*}{$\begin{array}{l}\text { Serial } \\
\text { No. }\end{array}$} & \multicolumn{3}{|c|}{$\%$ Error vs. fault distance (Fault Resistance $=20 \Omega$ ) } & \multicolumn{3}{|c|}{$\begin{array}{l}\% \text { Error vs. fault distance (Fault Resistance }= \\
60 \Omega \text { ) }\end{array}$} \\
\hline & $\begin{array}{l}\text { Fault Distance } \\
(\mathrm{Km})\end{array}$ & $\begin{array}{l}\text { Measured Fault } \\
\text { Location }\end{array}$ & $\begin{array}{l}\text { Percentage } \\
\text { Error }\end{array}$ & $\begin{array}{l}\text { Fault Distance } \\
(\mathrm{Km})\end{array}$ & $\begin{array}{l}\text { Measured } \quad \text { Fault } \\
\text { Location }\end{array}$ & $\begin{array}{l}\text { Percentage } \\
\text { Error }\end{array}$ \\
\hline 1 & 25 & 25.53 & 0.177 & 50 & 53.81 & 1.27 \\
\hline 2 & 75 & 75.18 & 0.06 & 100 & 103.12 & 1.04 \\
\hline 3 & 125 & 125.11 & 0.037 & 150 & 152.13 & 0.71 \\
\hline 4 & 175 & 175.16 & 0.053 & 200 & 202.88 & 0.96 \\
\hline 5 & 225 & 225.39 & 0.13 & 250 & 254.89 & 1.63 \\
\hline
\end{tabular}




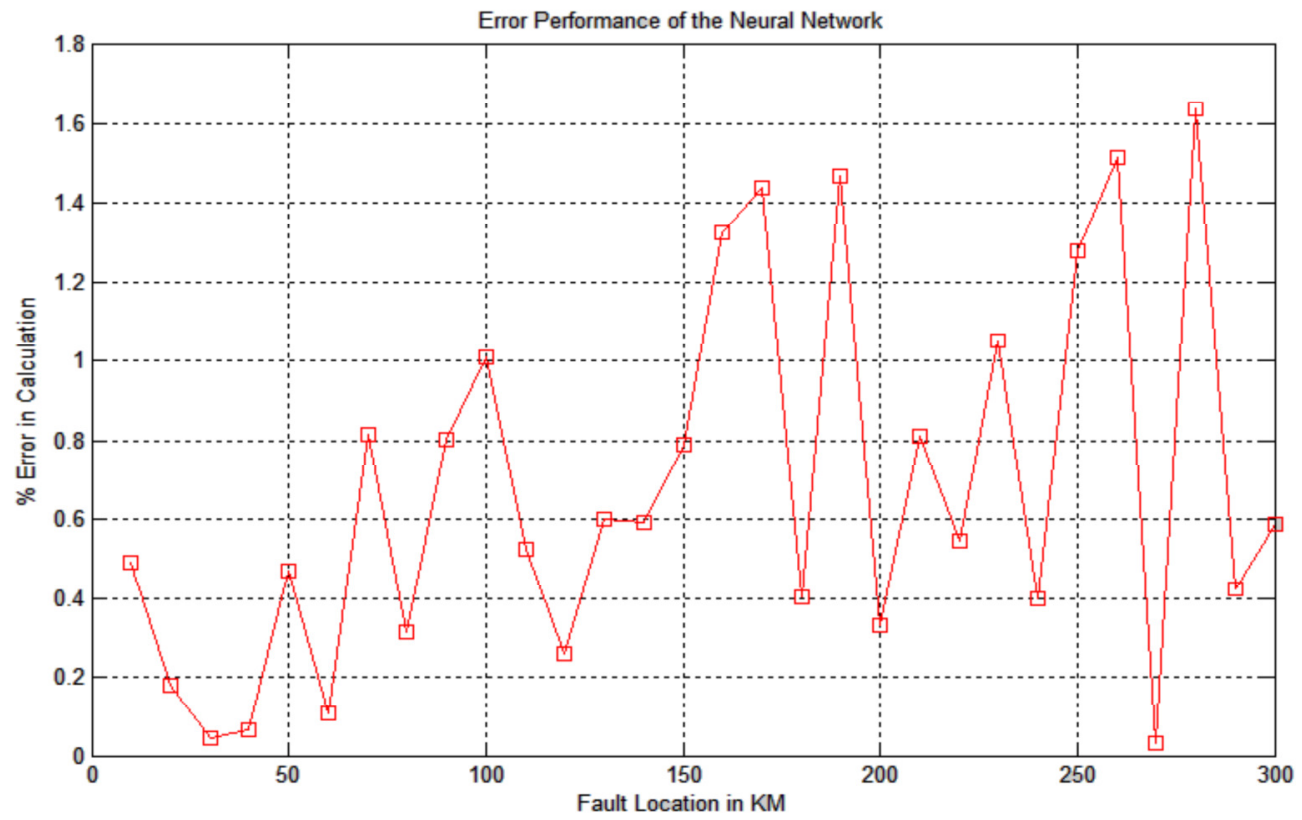

Figure 11: Test Phase performance of the ANN (6-6-21-16-1).

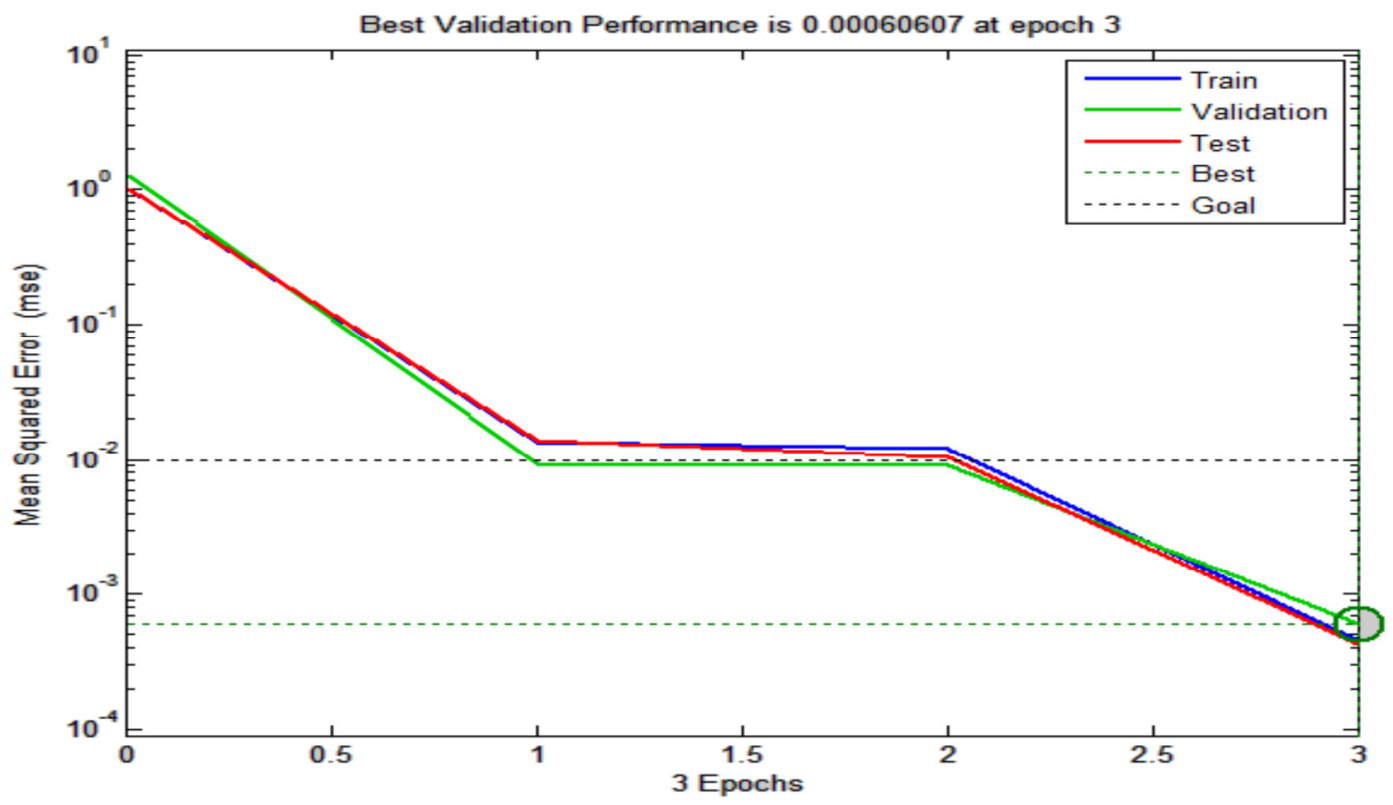

Figure 12: Mean Square Error performance of the neural network (6-6-21-16-1)

The value of $r$ in this case is found to be 0.99897 which is very close to 1 . It can be seen that the best MSE performance of this neural network is 0.00060607 (denoted by the dotted green line) which is below the MSE goal of 0.01 (denoted by the black dotted line). The test phase performance and mean square error performance of the network with configuration (6-6-21-16-1) are shown in Figure 11 and Figure 12 respectively.

Table 4 shows the percentage errors in Fault location as a function of Fault Distance and Fault Resistance. Two different cases have been considered (shown in adjacent columns), one with a fault resistance of 20 ohms and another with a fault resistance of $60 \mathrm{ohms}$.
It is to be noted that the resistance of $20 \mathrm{ohms}$ was used as a part of training data set and hence the average percentage error in fault location in this case is just $0.178 \%$. The second case illustrates the same with a different fault resistance of $60 \mathrm{ohms}$ which is relatively very high and is not a part of the training set. Hence, the performance of the neural network in this case illustrates its ability to generalize and react upon new data. It is to be noted that the average error in this case is just $0.836 \%$ which is still acceptable. Thus the neural networks performance is considered satisfactory and can be used for the purpose of three phase fault location 
Table 4: Percentage errors as a function of fault distance and fault resistance for the ANN chosen for three phase fault location.

\begin{tabular}{|c|c|c|c|c|c|c|}
\hline \multirow[t]{2}{*}{$\begin{array}{l}\text { Serial } \\
\text { No. }\end{array}$} & \multicolumn{3}{|c|}{$\%$ Error vs. fault distance (Fault Resistance $=20 \Omega$ ) } & \multicolumn{3}{|c|}{$\begin{array}{l}\text { \% Error vs. fault distance (Fault Resistance }= \\
60 \Omega \text { ) }\end{array}$} \\
\hline & $\begin{array}{l}\text { Fault Distance } \\
(\mathrm{km})\end{array}$ & $\begin{array}{l}\text { Measured Fault } \\
\text { Location }\end{array}$ & $\begin{array}{l}\text { Percentage } \\
\text { Error }\end{array}$ & $\begin{array}{l}\text { Fault Distance } \\
(\mathrm{km})\end{array}$ & $\begin{array}{l}\text { Measured Fault } \\
\text { Location }\end{array}$ & $\begin{array}{l}\text { Percentage } \\
\text { Error }\end{array}$ \\
\hline 1 & 25 & 25.51 & 0.17 & 50 & 53.41 & 0.47 \\
\hline 2 & 75 & 75.17 & 0.057 & 100 & 103.03 & 1.01 \\
\hline 3 & 125 & 125.52 & 0.28 & 150 & 152.37 & 0.79 \\
\hline 4 & 175 & 175.69 & 0.23 & 200 & 201.99 & 0.63 \\
\hline 5 & 225 & 225.46 & 0.1533 & 250 & 253.84 & 1.28 \\
\hline
\end{tabular}

\section{CONCLUSION}

An artificial neural network based fault diagnostic system has been developed for transmission line systems. It is comprised of four cascaded ANN blocks to perform four specific functions: (i) detection of fault occurrence, (ii) identification of faulted sections, and (iii) classification of faults into types. The multilayer feed-forward network with backpropagation learning algorithm is used for this purpose. In order to test its effectiveness, the proposed FDS has been tested on Apo 132KV transmission line system in Apo transmission substation, Abuja. It was found that the overall success rate of the FDS during training and testing stages was better than $96 \%$. The FDS structure lends itself easily to implementation such that the online diagnosis time is a small fraction of the measurement cycle. Moreover, the FDS has successfully identified faults in transmission lines, which are harder to detect with other schemes. The speed of the FDS will generally depend on the size of the computer processor being used. Real-time testing is the next step to confirm the practical usefulness of the proposed FDS in assisting the operator to initiate restoration procedures.

\section{REFERENCES}

[1] M.M. Adibi, R.W. Alexander and B.Avramovic, "Overvoltage control during restoration," IEEE Trans. Power Syst., vol. 7, no. 4, 1992, pp. 14641470.

[2] A.C. Westrom, A.P.S. Meliopoulos, G.J. Cokkinides and A.H. Ayoub, "Open conductor detector system," IEEE Trans. Power Delivery, 7, 1992, pp. 1643-1651.

[3] A.F. Sultan and G.W. Swift, "Detecting arcing downed-wires using fault current flicker and halfcycle asymmetry," IEEE Trans. Power Delivery, 8, 1993, pp. 554-561.

[4] W.H. Kwon, G.W. Lee, Y.M. Park, M.C. Yoon and M.H. Yoo, "High impedance fault detection utilizing incremental variance of normalized even order harmonic power," IEEE Trans. Power Delivery, vol. 6, no. 2, 1991, pp. 557-564.
[5] S. Ebron, D.L. Lubkeman and M. White, "A neural network approach to the detection of incipient faults on power distribution feeders," IEEE Trans. Power Delivery, vol. 5, no. 2, 1990 pp.905-914.

[6] A.E. Emanuel, D. Cyganski, J.A. Orr, S. Shiller and E.M. Gulachenski, "High impedance fault arcing on sandy soil in $15 \mathrm{kV}$ distribution feeders: contributions to the evaluation of the low frequency spectrum," IEEE Trans. Power Delivery, vol. 5, no. 2, 1990, pp. 676686.

[7] C.J. Kim and B.D. Russell, "High-impedance fault detection system using an adaptive element model," IEE Proc. C, vol. 140, 1993, pp. 153-159.

[8] D.I. Jeerings and J.R. Linders, "A practical protective relay for down-conductor faults," IEEE Trans. Power Delivery, vol. 6, no. 2, 1991,pp. 565-574.

[9] D.I. Jeerings and J.R. Linders, "Unique aspects of distribution system harmonics due to high impedance ground faults," IEEE Trans. Power Delivery, vol. 5, no.2, 1990, pp.1086-1094.

[10] C.J. Kim and B.D. Russell, "Classification of faults and switching events by inductive reasoning and expert system methodology," IEEE Trans. Power Delivery, vol. 4, no. 3, 1989, pp. 1631- 1637.

[11] J.W. Feltes, C. Grande-Moran, P. Duggan, S. Kalinowsky, M. Zamzam, V. C. Kotecha and F.P. de Mello, "Some considerations in the development of restoration plans for electric utilities serving large metropolitan area," IEEE Trans. Power Syst., vol.21, no. 2, 2006, pp. 909-915.

[12] I. Sadeghkhani, A. Ketabi, and R. Feuillet, "New Approach to Harmonic Overvoltage Reduction during Transformer Energization via Controlled Switching," in Proc. 15 ${ }^{\text {th }}$ International Conference on Intelligent System Applications to Power Systems, Curitiba, Brazil 2009.

[13] A. J. Mazon, I. Zamora, J. Gracia, K. Sagastabeitia, P. Eguia, F. Jurado and J. R. Saenz, "Fault Location System on Double Circuit Two-Terminal Transmission Lines Based on ANN'S",IEEE Power Tech Proceedings, Porto, Vol. 3, 10 -13 Sep 2001.

[14] M. M. Saha, J. Izykowski and E. Rosolowski, Fault Location on Power Networks, Springer Publications, 2010. 
[15] F. H. Magnago and A. Abur, "Advanced techniques for transmission and distribution system fault location", Proceedings of CIGRE - Study committee 34 Colloquium and Meeting, Florence, paper 215, 1999.

[16] Y. Tang, H. F. Wang, and R. K. Aggarwal, "Fault indicators in transmission and distribution systems", Proceedings of International conference on Electric Utility Deregulation and Restructuring and Power Technologies - DRPT, London, pp. 238$243,2000$.

[17] C.C. Nnobi-Okoye and A. C. Igboanugo, "Predicting water levels at Kainji Dam using artificial neural networks", Nigerian Journal of Technology Vol. 12, No.1, March 2013, pp. 129 - 136.

[18] S. Y. Musa and E. V. Mbaga, "Daily Nigerian peak load Forecasting using Artificial Neural Network with Seasonal Indices", Nigerian Journal of Technology, Vol. 33, No. 1, January 2014, pp. 114 118.

[19] A. W. Salami, A. A. Mohammed, J. A. Adeyemo and O. K. Olanlokun, "Modeling of reservoir inflow for Hydropower Dams using Artificial Neural Network", Nigerian Journal of Technology, Vol. 34, No. 1, January 2015. 